\title{
DSC EXAMINATIONS ON CATARACTOUS LENS MATERIALS OBTAINED BY PHACOEMULSIFICATION
}

\author{
Zs. Biró ${ }^{1}$, Vanda Nemes ${ }^{1}$, G. A. Molnár ${ }^{2}$, I. Wittmann $^{2}$, Andrea Ludány ${ }^{3}$ and D. Lórinczy ${ }^{4 *}$ \\ ${ }^{1}$ Department of Ophthalmology, University of Pécs, 7624 Pécs, Szigeti street 12, Hungary \\ ${ }^{2} 2^{\text {nd }}$ Department of Medicine and Nephrological Center, University of Pécs, 7624 Pécs, Szigeti street 12, Hungary \\ ${ }^{3}$ Department of Laboratory Medicine, University of Pécs, 7624 Pécs, Szigeti street 12, Hungary \\ ${ }^{4}$ Department of Biophysics, Faculty of Medicine, University of Pécs, 7624 Pécs, Szigeti street 12, Hungary
}

\begin{abstract}
Modifications of lens proteins play a crucial role in the formation of cataract, which is among the leading causes of world blindness in the ageing population. Although modern cataract surgery by phacoemulsification is a very successful and safe procedure, the prevention of cataract formation would be a real breakthrough in this field of ophthalmology.

The aim of our study was to analyse the thermal denaturation of the cataractous lens proteins by the method of differential scanning calorimetry (DSC), to understand cataract formation and to work on its prevention possibilities. Samples were obtained from cataract patients of different age, sex, patients with and without diabetes mellitus. Samples were obtained from lenses of mature degree and progredient degree of cataract as well.

Previous DSC examinations were performed on manually extracted human cataractous lens materials, however to the best of our knowledge, this is the first study, in which DSC examinations were performed on lens materials obtained by the phacoemulsification technique, which gained acceptance world-wide in the last decade.
\end{abstract}

Keywords: cataract, diabetes, DSC, phacoemulsification

\section{Introduction}

Cataract formation is a major problem in health systems due to an increasing demand for cataract surgery, and still today cataract is the most common cause of blindness. The crystalline lens is a unique organ in many regards. It is avascular, it has a high cellular protein concentration, despite the high protein concentration still transparent for visible light, and it has an extremely low protein turnover. Since the lens is avascular i.e. possesses no direct blood supply, and is surrounded by the lens capsule, it represents a unique, relatively closed system. As a consequence of the low protein turnover, the physico-chemical effects from the inner and outer environment on the lens cumulate and lead to the development of opacification with age [1-7].

Nowadays, despite the extensive literature $[1-3,8-11]$, the lens is still of great interest in the pathologic and physiologic researches. The biochemical analysis of tissue culture, animal and human samples deal with the ethiopathogenesis of cataract with special regard to proteins [3, 12-14].

The metabolic disturbances such as hyperglycaemia affect the composition of lens proteins, this way they contribute to cataract formation. The high glucose concentration evokes oxidative stress among others due to the damaged intracellular metabolism, the polyol-pathway and non-enzymatic glycation reactions $[1,11]$. In non-diabetic subjects free radicals formed during ageing processes may also contribute to age-related cataract formation.

Previous DSC examinations were performed [12-15] on manually extracted human cataractous lens materials, however to the best of our knowledge, this is the first study, in which DSC examinations were performed on lens materials obtained by the phacoemulsification technique, which gained acceptance world-wide in the last decade.

In our paper - based on the experience of Biophysical Department in the field of biological macromolecules [16-19] - we present novel results of our studies of the DSC examinations on cataractous lens proteins. In our article we include the results of previous electrophoresis studies [20] of the soluble and insoluble protein fractions in one hand, and we present post-transactional modifications of amino acid residues on the other hand. Changes due to oxidative stress were also investigated by high performance liquid chromatographic (HPLC) technique for measurement of the levels of amino acids formed by the oxidative modification of phenylalanine. 


\section{Experimental}

Materials and methods

Cataractous lens preparation

We examined cataractous human lenses that were removed during extracapsular cataract extraction surgery by phacoemulsification, upon informed consent. All cataractous lenses (from 17 eyes of 17 patients) were removed under the same circumstances by the same surgeon. The Ethical Board of the Medical Faculty of the University of Pécs approved the study on lens proteins after cataract extraction.

Lens materials were examined and compared between diabetic $(n=1)$ and non-diabetic $(n=16)$ patients, younger ( $n=2$, less than 60 years) and older $(n=15$, older than 70 years) patients and between males and females. An important factor was the degree of cataract. Most of the samples were from progredient cataract, while one sample was from a mature cataract. Main clinical characteristics of the patients are shown in Table 1.

Table 1 The amount of the hydroxyl free radical markers (area under the HPLC curves) in non-diabetic patients corrected for phenylanine

\begin{tabular}{llcc}
\hline \multicolumn{4}{c}{ Non-diabetic lenses } \\
\hline & Control & $\begin{array}{c}\text { Progredient } \\
\text { cataract }\end{array}$ & $\begin{array}{c}\text { Matur } \\
\text { cataract }\end{array}$ \\
\hline DOPA/Phe & 1.637 & 2.129 & 1.843 \\
$m$-Tyr/Phe & 0 & 0.426 & 1.247 \\
$o$-Tyr/Phe & 1.037 & 1.077 & 2.999 \\
\hline
\end{tabular}

Surgery was carried out under topical anaesthesia through a $3.2 \mathrm{~mm}$ long 'clear corneal' incision after dilation of the pupil. Capsulorhexis was performed under viscoelastic material and was followed by hydrodissection and rotation of the lens nucleus. The lens nucleus was removed by a 'divide and conquer' phacoemulsification technique, the cortex by irrigation-aspiration. The posterior capsule was polished and vacuum-cleaned when needed, and a foldable artificial len was implanted into the capsular bag under viscoelastic material, after wound enlargement. Viscoelastic material was then washed out thorougly and operation was finished by giving subconjunctival gentamycine and dexamethasone injection.

The specimen from the surgical medium was extracted immediately after surgery by centrifugation for $30 \mathrm{~min}$ by $3000 \mathrm{rpm}$.

\section{Gel-electrophoresis}

Lens proteins were separated by gel electrophoresis according to Laemmli [21]. Detection of protein fractions was performed by silver identification, and the dyed gels were assessed by direct densitometry.
High performance liquid chromatography (HPLC)

Measurement of amino acid composition of lens proteins was carried out by HPLC analysis by the method, described by Ishimitsu [22]. Quantitative analysis of the amino acids was carried out using the Licrospher- $\mathrm{C}_{18}$ silica column (Merk) Tyr (tyrosine) isoforms and DOPA (3,4-dihydroxy-phenylalanine) were measured at $258 \mathrm{~nm}$ excitation and $305 \mathrm{~nm}$ emission, while Phe (phenylalanine) at 258 excitation and $288 \mathrm{~nm}$ emission using a Shimadzu RF-10A $\mathrm{AL}_{\mathrm{XL}}$ fluorescent detector. The areas under the curve were determined for the amino acids. The amino acid concentrations were corrected for protein content or Phe concentrations as well.

\section{Differential scanning calorimetry (DSC)}

Thermal unfolding of lens proteins in different states of cataract and patients was monitored by a Setaram Micro DSC-II calorimeter. All experiments were conducted between 0 and $100^{\circ} \mathrm{C}$. The heating rate was $0.3 \mathrm{~K} \mathrm{~min}^{-1}$ in all cases. Conventional Hastelloy batch vessels were used during the denaturation experiments with $850 \mu \mathrm{L}$ sample volume (phacoemulsificated lens proteins suspension) in average. Phacoemulsification infusion was used as a reference sample. The sample and reference vessels were equilibrated with a precision of $\pm 0.1 \mathrm{mg}$. There was no need to do any correction between the heat capacity of sample and reference vessels during the evaluation of DSC scans. The repeated scan of denatured sample was used as baseline reference, which was subtracted from the original DSC curve. Calorimetric enthalpy change was calculated from the area under the heat absorption curve by using two-point setting Setaram peak integration.

\section{Results and discussion}

\section{Gel-electrophoresis studies}

In our previous study [20] lens fragments were derived from the surgical medium by centrifugation. Samples were homogenized in a buffered medium containing protease inhibitor. Soluble and insoluble protein fractions were separated by centrifugation. The electrophoresis studies were performed according to Laemmli [21] on equal amounts of proteins and were followed by silver intensification (Fig. 1). Among lens proteins, the presence of proteins in the range between 20-30 kDa was characteristic for each sample (Fig. 1). According to densitometry measurements, this group represented $30 \%$ of the electrophoretised proteins. 


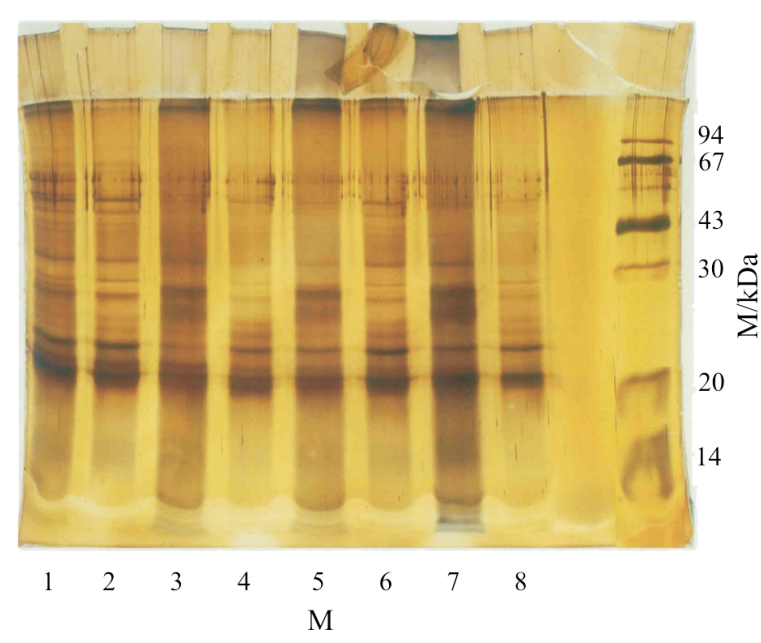

Fig. 1 SDS polyacrylamid-gel-electrophoretogram of the lens homogenate and soluble protein. $12.5 \%$ gel, coomassie brilliant blue colouring, silver intensification. Control samples (1-2), diabetic cataract (3-6), non-diabetic mature cataract (7-8), total homogenate $(1,3,5,7)$, solubile fraction $(2,4,6,8) ; M$ - molecular mass

\section{High performance liquid chromatographic (HPLC) studies}

Using the HPLC methods with fluorescein detection and wavelength change, the amount of the hydroxyl free radical markers $m$-Tyr (meta-tyrosine), $o$-Tyr (ortho-tyrosine) and DOPA could be well detected in the total lens homogenates (oxidized amino acid content of the samples was also analysed by HPLC following $\mathrm{HCl}$ hydrolysis of proteins). A representative chromatogram is shown on Fig. 2.

Our results showed that soluble proteins represented a significantly lower portion of the total protein content in cataractous lenses, and the crystalline-like proteins with low-molecular mass can be found both in the soluble and insoluble fractions. In our HPLC analysis, oxidatively modified derivatives of phenylalanine were detected in cataractous samples. We found an accumulation of $m$-Tyr, $o$-Tyr and

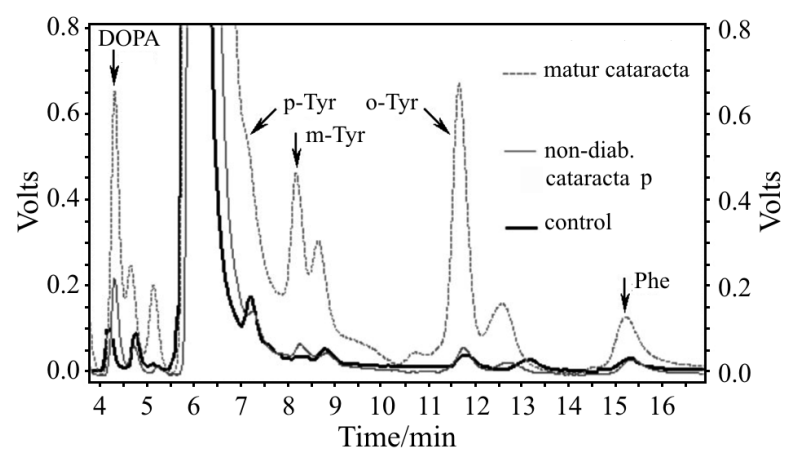

Fig. 2 HPLC analysis of control and non-diabetic cataractous lenses. Symbols: DOPA: $L$-dihydroxy-phenylalanine, $p$-Tyr: $L$-paratyrosin, $m$-Tyr: $L$-metatyrosin, $o$-Tyro $L$-orthotyrosin, Phe: $L$-phenylalanine

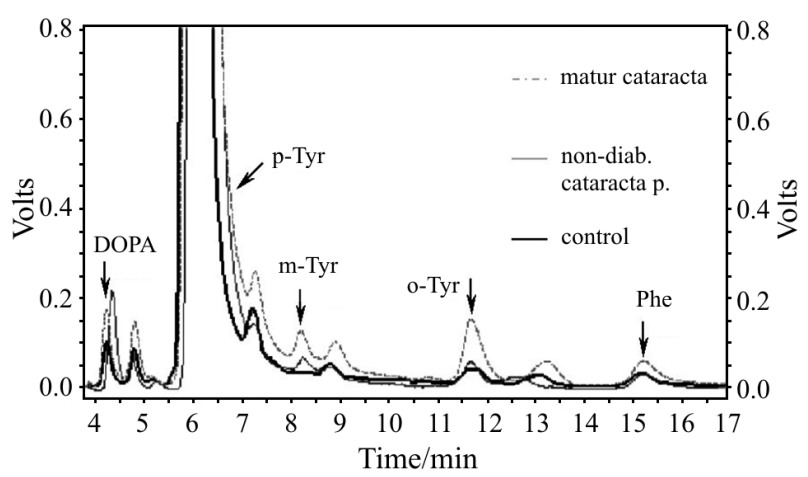

Fig. 3 HPLC analysis of control, diabetic and non-diabetic cataractous lenses. Symbols are the same as in Fig. 2

DOPA in the total homogenates of cataractous samples compared to the supernatants. The accumulation of $m$ - and $o$-Tyr is an indicator of oxidative stress, their amount is increasing as the stage of cataractous lens is more serious (Table 1). Comparing the samples of non-diabetic and diabetic lenses (Fig. 3) in the $m$ - and $o$-Tyr compounds we can see an increase in diabetic case while the DOPA does not show a similar tendency (Table 2).

Table 2 The amount of the hydroxyl free radical markers (area under the HPLC curves) in diabetic and non-diabetic patients corrected for phenylalanine

\begin{tabular}{lcccc}
\hline & \multicolumn{2}{c}{ Non-diabetic lenses } & & Diabetic lenses \\
\hline & Control & $\begin{array}{c}\text { Progredient } \\
\text { cataract }\end{array}$ & & $\begin{array}{c}\text { Progredient } \\
\text { cataract }\end{array}$ \\
\cline { 1 - 2 } \cline { 5 - 5 } DOPA/Phe & 1.637 & 2.129 & & 1.097 \\
$m$-Tyr/Phe & 0 & 0.426 & & 0.597 \\
$o-\mathrm{Tyr} /$ Phe & 1.037 & 1.077 & & 1.951 \\
\hline
\end{tabular}

\section{DSC results}

In the progredient group of eyes $(n=16)$ the DSC (two meltings at $68-85^{\circ} \mathrm{C}$ ) showed difference in calorimetric enthalpy between the female and the male groups in the function of age as well as sex (Fig. 4). In one mature cataract the difference was significant in the lower melting temperature. The one lens material obtained from a diabetic patient showed alteration in the second melting. Both of them are indicating the damage of the lens proteins. The incipient sample had two low meltings (Fig. 5 and Table 3).

The dynamic, close interaction-taking place between lens components plays a crucial role in the maintenance of lens transparency. During ageing, the water, ion and protein content of the lens change even under physiologic conditions. As long as the protecting mechanisms are able to counterbalance the physico-chemical influences of the environment on the lens, it maintains its transparency. Development of cataract always indicates that harmful influences exhaust defending mechanisms of the organ. 


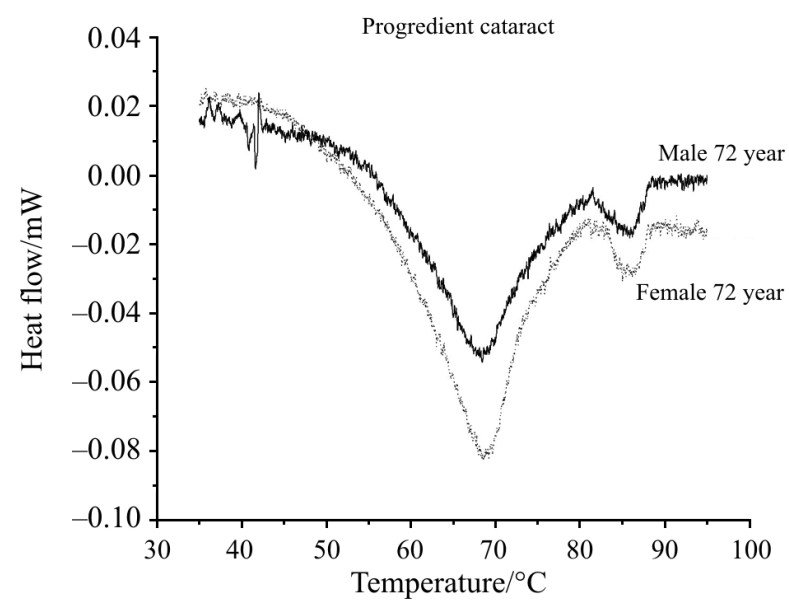

Fig. 4 Thermal denaturation of female (dotted line) and male (solid line) progredient cataractous lenses

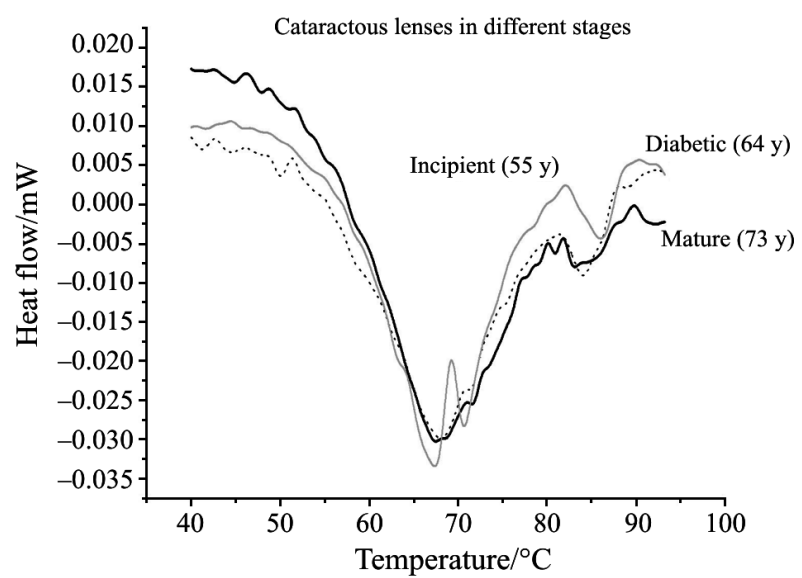

Fig. 5 Melting behaviour of cataractous lenses in different stages of cataract. Mature: solid, diabetic: dotted and incipient with gray line

Table 3 Thermal parameters of human lens proteins (Symbols: $T_{\mathrm{m}}=$ melting temperature, $\Delta H=$ calorimetric enthalpy change, $n=$ number of samples, data with * are in average \pm s.d.)

\begin{tabular}{lccc}
\hline & $T_{\mathrm{m} 1} /{ }^{\circ} \mathrm{C}$ & $T_{\mathrm{m} 2} /{ }^{\circ} \mathrm{C}$ & $\Delta H / \mathrm{J} \mathrm{g}^{-1}$ \\
\hline $\begin{array}{l}\text { Progredient* } \\
\text { (female } n=9)\end{array}$ & $68.3 \pm 0.2$ & $85 \pm 0.2$ & $0.23 \pm 0.02$ \\
$\begin{array}{l}\text { Progredient* } \\
\text { (male } n=5)\end{array}$ & $68.2 \pm 0.1$ & $84.9 \pm 0.2$ & $0.18 \pm 0.02$ \\
$\begin{array}{l}\text { Mature } \\
\text { (female } n=1)\end{array}$ & 67.6 & 84.7 & 0.13 \\
$\begin{array}{l}\text { Diabetic } \\
\text { (male } n=1)\end{array}$ & 68 & 84 & 0.13 \\
$\begin{array}{l}\text { Incipient } \\
\text { (male } n=1)\end{array}$ & $67.1 ; 70.5$ & 85.9 & 0.14 \\
\hline
\end{tabular}

According to MRI studies, the majority of the water content of the lens is so-called bound water, and its ratio varies inside the lens as well. Changes in the total water content and significant decrease of bound water has been well proven in cataractous lens [23].
All the changes taking place in the soluble and insoluble fractions of the lens proteins are simultaneously reflected in a shift of the ratio of the bound fraction. In such cases, the denatured proteins loose their close relation with water; protein-protein associations alter and form molecular aggregates [8-10,24].

In our study, we investigated cataractous lenses by DSC. This way we could compare the melting temperatures of the lens proteins of diabetic and non-diabetic cataract, the characteristics of older and younger patients, males and females. According to our findings, sex, age and the stage of cataract have effect on melting of lens proteins of cataractous lenses. Significant differences were observed in the calorimetric enthalpies in the function of sex, and in the melting temperatures in case of incipient lens.

To the best of our knowledge, this is the first study of DSC examinations performed on human cataractous crystalline lens material obtained by the modern surgical technique of phacoemulsification.

\section{Acknowledgements}

The Setaram Micro DSC-II used in the experiments was purchased with fund provided by the National Research Foundation Grant CO-272.

\section{References}

1 M. A. Van Boekel and H. J. Hoenders, FEBS Letters, 314 (1992) 1.

2 S. Fu, R. Dean, M. Southan and R. Truscott, J. Biol. Chem., 273 (1998) 28603.

3 M. C. Wells-Knecht, T. G. Huggins, D. G. Dyer, S. R. Thorpe and J. W. Baynes, J. Biol. Chem., 268 (1993) 12348.

4 H. Bloemendal, W. de Jong, R. Jaenicke, N. H. Lubsen, C. Slingsby and A. Tardieu, Progr. Biophys. Mol. Biol., 86 (2004) 407.

5 M. J. Davies, S. Fu, H. Wang and R. T. Dean, Free Rad. Biol. Med., 27 (1999) 1151.

6 I. Siebinga, G. F. Vrensen, K. Otto, G. J. Puppels, F. F. De Mul and J. Greve, Exp. Eye. Res., 54 (1992) 759.

7 E. R. Stadtman and R. L. Levine, Amino Acids, 25 (2003) 207.

8 Adler's physiology of the eye. (Ed.: Williams M. Hart, $9^{\text {th }}$ Edition) Mosby Year Book Inc., 1992, pp. 348-90.

9 A. J. Bron, G. F. Vrensen, J. Koretz, G. Maraini and J. J. Harding, Opthalmologica, 214 (2000) 86.

10 L. T. Chylack Jr., Ophthalmology, 91 (1984) 596.

11 A. J. Bron, J. Sparrow, N. A. Brown, J. J. Harding and R. Blakytny, Eye, 7 (1993) 260.

12 F. A. Bettelheim, J. A. Castoro, O. White and L. T. Chylack Jr., Curr. Eye Res., 5 (1986) 925.

13 F. A. Bettelheim and N. Popdimitrova, Exp. Eye Res., 50 (1990) 715.

14 H. Wang and F. A. Bettelheim, Exp. Eye Res., 55 (1992) 387. 


\section{DSC STUDY ON CATARACTOUS LENS PROTEINS}

15 F. A. Bettelheim, L. Li and F. F. Zeng, Res. Comm. Mol. Pathol. Pharmacol., 102 (1998) 3.

16 M. Kiss, J. Belagyi and D. Lörinczy, J. Therm. Anal. Cal., 72 (2003) 565.

17 D. Lörinczy, M. Kiss and J. Belagyi, J. Therm. Anal. Cal., 72 (2003) 573.

18 T. Sillinger, P. Than, B. Kocsis and D. Lörinczy, J. Therm. Anal. Cal., 82 (2005) 221.

19 B. Schäffer, S. Szakály and D. Lőrinczy, J. Therm. Anal. Cal., 82 (2005) 537.

20 Zs. Biró, V. Nemes, I. Wittmann, G. A. Molnár, B. Kocsis and A. Ludány, Szemészet, 140 (2003) 67 (in Hungarian).

21 U. K. Laemmli, Nature, 27 (1970) 680.
22 S. Ishimitsu, S. Fujimoto and A. Ohara, J. Chromatogr., 378 (1986) 222.

23 P. Rácz, C. Hargitai, B. Alföldy, P. Bánki and K. Tompa, Exp. Eye Res., 70 (2000) 529.

24 J. Bours, H. J. Fodisch and O. Hockwin, Ophthalmic Res., 19 (1987) 235.

Received: May 23, 2005

In revised form: August 15, 2005

OnlineFirst: January 11, 2006

DOI: $10.1007 / \mathrm{s} 10973-005-7113-\mathrm{x}$ 